\title{
The Educational Aspects of Integrating Popular Music into Lessons
}

\author{
Asta Rauduvaite Dr. paed. \\ Lithuanian University of Educational Sciences, Lithuania \\ asta.rauduvaite@leu.lt
}

\begin{abstract}
Solving the pedagogical dilemma of popular music a number of questions arouse: can popular music educate? How can it educate? What factors predetermine the educational impact of popular music? How to differentiate between appropriate and inappropriate music? Or perhaps, popular music is a problem of society's culture, then how to solve this problem? Is popular music a sign of bad taste? Can we perceive values in popular music under changing moral norms? Is music evaluated using norms of "elite" music? The formulated questions allow to state that the influence of popular music on school learners is undisputed, therefore, it is significant to search for ways to use it in primary education. The goal is to reveal educational possibilities of popular music integration applying active education methods in music lessons of primary formers. The research is based on the educational project, which was implemented in the 2nd-4th forms of primary school. Choosing characteristic popular music compositions and evoking school learners' artistic experiences, the idea of personal meaning and emotional imitation methods were regarded as important during the educational project. This is supremely significant conveying a specific perception of music. The research on enrichment of music curriculum with attractive music forms disclosed that popular music occupies an exceptional place in the music value scale of learners, provides experience of positive emotions and can serve as a meaningful means for promotion of value-based attitudes of junior school learners. Integration of popular music into primary music education helps to implement one of the most important goals - to provide necessary music education, which would contribute to creating foundations for self-perception and positive relations with other people.
\end{abstract}

Keywords: primary music education, popular music, active methods, school education.

\section{Introduction}

The aim to address the challenges imposed by the 21 st century has been observed in contemporary theory and practice of pedagogy, which include implementation of life-long learning, assurance of education quality, preparation of an individual for life and successful professional activity under rapidly changing social and cultural conditions. Education today should be understood as the main power that modernises society and as a prerequisite for success in every person's life, whereas learning is acknowledged as a crucial factor for personal improvement. Indicating the direction of education in the General Curricular of Primary and Basic Education of Lithuania (Pradinio ir pagrindinio..., 2008), it is stated that the content of education answers new challenges imposed on education, i.e., rapid change in social and economic life and expanding possibilities for implementation of education innovations. School learners have to acquire necessary knowledge and understanding, to develop key abilities and value-based attitudes. Therefore, formulating the goals of education, it is appropriate to consider the factors that might have influence and to retain the link of the learner himself or herself with reality.

Popular music reveals itself as a holistic factor of school learners' life experience and becomes an inseparable part of their life in the period of changes in socio-cultural life, development of information society, value transformations and changes in form and content of music. School learners accept musical information declared by contemporary environment with admiration and this information naturally derives from their practical activities but does not always have a positive influence on development of their esthetical taste (Piliciauskas, 1998; Juvonen, 2002; Rauduvaite, 2016). Multi-faceted change in music culture requires from teachers the ability to orient in the space of changes, to flexibly use the new opening possibilities of music, to help a learner the change of contemporary music culture, to develop learners' music experience, to foster their emotional maturity through the emotional relation with music, to presuppose their general abilities and value-based attitudes. The challenges of changing society encourage teachers to remain in close contact to the musical environment that is close to school learners, to employ possibilities of popular music searching for closer interaction between music culture and education.

The methods and their choice acquire utmost importance in the process of education. Recently in Lithuania attempts have been made to evoke school learners' interest in various kinds of music searching for various methods that activate their musical activities. Regardless of the variety of methods for 
musical educational activities, the research on the revelation of the educational potential of popular music and practical application of active music education methods as well as relevant teaching aids are insufficient in Lithuania.

However, more frequently educational potential of popular music has been a research focus among foreign scholars (Wright, Finney, 2010; Davis, Blair, 2011; Mantie, 2013; Sepp, Ruokonen, 2013; Mark, Madera, 2014; Springer, Gooding, 2013). Researchers also suggest reducing the gap between education curricular and music interests of contemporary school learners, their abilities, school needs through creating a new context of music teaching (Juvonen, 2002; Nilsson, Folkestad, 2005; Green, 2006; Hedden, 2010; Juvonen, Ruismaki, Lehtonen, 2012; Bowman, 2012; Rodriguez, 2012; Carvalho, Scavarda, 2014; Law, Ho, 2015).

The Lithuanian educational researcher addreses various problem issues related to music education discussing peculiarities of expression in school learner's music activities and perspectives of its improvement. However, the influence of popular music developing value-based attitudes of a child as a maturating personality and practical application of active music education methods (personal meaning and emotional imitation) during lessons have not been exhaustively analysed so far. Therefore, it is necessary to search for activities that allow to integrate popular music not only for improvement of education curriculum but also for nurturance of child's personal value-based attitudes simultaneously understanding the changing situation of music education curriculum in the context of contemporary music culture.

The aim of the study is to reveal educational possibilities of popular music integration applying active educational methods in music lessons of primary learners.

\section{Methodology}

Seeking to analyse the integration of popular music into primary education, the educational project with second-fourth formers in primary education in one of the classical gymnasiums of the city was chosen as the basis of the empirical research. The sample of the educational project included 70 school learners. The project was conducted in the school year of 2016-2017.

The essence of the educational project relies on the search for or creation of new components of pedagogical reality at the junction of practice-based scientific cognition and innovative educational activity (Charvat, 2003). In other words, this includes an educational process based on a new (or relatively new but relevant) idea that is created under the researcher's initiative through shared attempts of the researcher and participants in this process. The educational project is considered to be a specific method for approbation of an educational idea. The purpose of the educational project is to test if a pedagogical idea suggested by the researcher is realistic and acceptable to participants in the process of education. The method of educational project sets priority for the analysis of new educational phenomena, solution of socially relevant educational problems and introduction of innovative educational technologies. Therefore, the method of educational project was chosen for the analysis the educational role of popular music as a contemporary socio-cultural phenomenon.

Applying active music education methods during the educational project, the method of personal meaning suggested by A. Piliciauskas was seen as central. According to the author, having realised the personal meaning of the impact of a musical composition, the performer "cannot remain an indifferent observer of events because presenting a piece of music to a listener she or he presents herself or himself: ideals, beliefs and principles of spiritual life" (Piliciauskas, 1998, 227). To enable a school learner to have what to feel and experience, the artistically valuable repertoire of pop music was chosen, which included compositions and arrangements created by professional composers. A considerable attention was allotted to the analysis of musical intonation, instrumental accompaniment, the link between poetical text and music. Another aim was to reveal specifics of the effect of means of musical expression on the listener and the performer and to create condition for experiencing a piece of music. The emotional sensation was considered a relevant link in raising musical awareness of children at this school age period. According to A. Piliciauskas (1998), emotional experiences and the attitude to reality predetermine the variety of behaviour states.

The pedagogical idea, i.e. a method of emotional imitation, suggested by L. Navickiene (2005) is equally important here. This is a method of promoting school learners' musicality and musical abilities as well as their self-education imitating the content of emotional intonations of a composition or experiences of 
an imaginary character, which is evoked with the help of integration of other kinds of art. Seeking to provide emotional images with moral direction, L. Navickiene relies on certain intents of musical activities, i.e. a complex of informative and laconic questions, which can embrace all the life spheres and analyse relevant problems. Intents of musical activity direct school learners to the targeted verbalisation of experiences.

During the educational project attempts were made to ensure that music experiences acquired through popular music enhance school students' fascination with human values and motivate them to sensation of the good and the beautiful. An exceptional focus is laid on identification-verbalisation of musical experiences as on an important pedagogical means for understanding the effect of music. In other words, to enable school learners to understand the individual's internal world expressed through means of popular music, they have as if to enter the world of this musical composition, to act in the imaginary situation and, with the help of the teacher, to verbalise experienced individual emotions. Though school learners experience positive and negative emotions, but positive emotions are more frequent in favourite activities. During music lessons school learners were encouraged to present feelings and thoughts evoked by listening to or performing music and to explain the choice of one or another composition of popular music.

The research was conducted applying several methods: analysis of scholarly literature and documents and the educational project.

\section{Results and Discussion}

The concept of popular music in the article is determined in the following way: popular music includes pieces of music of wide appeal, which are well known, frequently performed and represent different genres and styles. It is also appropriate to exclude one more structural component in the variety of popular music, i.e. popular music to primary schoolchildren. In other words, taking into account currently relevant issues, it is necessary to distinguish and determine popular music that aims at improvement of educational curriculum, i.e. is meant for listening to or performing by school children, and at encouragement of dynamics in their value-based attitudes.

Following the idea of personal meaning and principles of emotional imitation applying popular music and seeking to illustrate the presented statements, examples of various musical activities, i.e. modelling of activity intents before a certain action, are presented. The discussions that encourage school learners to ground their opinion, decisions and promote autonomy of decisions made and that are initiated by the teacher become of utmost importance in such activities.

The episode of listening to "The Return of Spring" by D. and G. Gibsons, which was applied during the educational research, is presented below. The prevailing intent of the activity is Concern about others.

Introductory conversation. The spring outside: regenerated nature and songs of homing birds in the nests. However, not all of them find their "homes", as some bird nests are taken or ruined. Everybody wants to be happy and welcomed in their cosy home. Listening to bird voices heard in music, read the riddle: how do the birds feel? What moods (joy, happiness, disappointment, surprise, sorrow) do birds go through? (the music composition also contains natural sounds of nature: bird voices, chatter of river, sighing of trees, crackle of branches, whisper of leaves, whirls of wind and spitting of the burning fire. All this may contribute to conveying and feeling specific and interesting combination of nature and contemporary music sounds; to listen to bird sounds and new music intonation patterns. Having heard the composition, school children are asked: what did you go through? What experiences were evoked? What are the reasons for such experiences? (e.g., each bird helps each other just like people can help each other...).

Attempts are made to enable every learner to establish a unique and individual relation with music, to envisage values in them, to be able to admire them and explain the importance of means of music expression to the artistic image of a composition. It is important for a teacher to be an example evaluating music and diverting school learners' statements towards certain direction, i.e. towards sincere, open, emotional sharing of impressions to enable school learners to freely determine and indicate what values nurtured by them are evoked by music.

While organising musical activities during the lesson, organisational challenges are faced. Learners do not tend to share their emotional experiences easily. An unconventional answer provided by a school 
student should not be perceived as ignorance. Firstly, they should feel that their opinion is interesting and appreciated.

The main condition for seeking better learning outcomes is school learner's psychological safety, therefore it is necessary to create favourable climate for a child in the classroom. A school learner should not be afraid to ask, make mistakes and to have own opinion different from that of the majority. It is particularly important to help learners to perceive what they feel during musical activities, to convey the content of their emotions, to listen to their opinion about problems that evoke their concern searching for jointly generated answers to the issues worrying them. It is appropriate to ensure that during musical activities schoolchildren learn to respect others and themselves, enjoy attained success, develop ability to listen to the opinion of others just as they listen to the sounding music.

The episode of teaching the song "Mom" (music by R. Sileika, lyrics by D. Teiserskyte) created by contemporary authors and applied in the educational project is presented with Sincerity as prevailing attitude.

Introductory conversation. Do you know that your appreciation, support and sincerity are the greatest gifts to your Mom? You are Love, Concern and Anxiety to your Mom. How many nice nuances the word "mother" may have: mummy, mom, mam. This word sounds in your language daily. But sometimes it happens that children say some disrespectful and insulting words (perhaps not deliberately and without any bad intentions). I think that you agree with me that such behaviour is inappropriate. I would like to believe that you do not behave like this. The future of our society depends on the relation between the mother and the child (relations of people). The value of a person is predetermined not by his/her appearance but rather by the internal world and attitude towards the life values. We are going to listen to the music (instrumental phonogram) of the song "Mom" written by a contemporary composer (live performance of the teacher is also possible). While listening to the sounds of music, try to empathise with and imagine the world of mom's (grandma's) thoughts, the state of her feelings (perhaps she is happy: her children are good school learners and help her at home; or perhaps she is worried or calm). Having listened to the song and discussed the lyrics, the melody is taught. Later, after learning the melody, heuristic elements are presented; school learners express characteristics of related emotional states.

Using popular music in musical activities, the following opinions of school learners about this kind of music were highlighted: "popular music differs from unpopular because it evokes nice feelings and moments"; "popular music is trendy; everybody likes it"; "pop music is popular all over the world and nobody can resist it"; "this is music, which is nice to you and is not expensive at all"; "this is, when a person listens a lot to the same music"; "this is music, which you are never bored of"; "music is popular as it is listened by many people".

The practice of education shows that integrating various kinds of music into musical activities not only facilitates development of school learners' musical thinking, trains memory, self-expression but also teaches to concentrate, to focus attention, to hear oneself and others. Moreover, nurturing children's inborn musicality, their esthetical awareness, need for performing music, artistic perception of music, musical ear, voice, memory as well as areas of emotions and feelings are also developed.

Discussing musical experiences, it is important to help children learn their own best qualities, to encourage children to develop them, to enhance self-assessment and to encourage them to ground their behaviour on the discussed values (Rauduvaite, 2016).

Emotional experiences verbalised by school learners reveal the picture of musical activities, when popular music is applied. Singing is one of the most accessible musical activities for school learners in this age group to express themselves using a very sensitive and individual instrument, i.e. their voice. The opinion of school learners about learning to sing: "You can express your feeling through singing. People like singing"; "A person needs singing because singing is relaxing and people would be gloomy without it"; "I am happy and I want to sing and sing"; "Singing is music spread by a person himself or herself"; "I like songs because you listen to words attentively"; "A singing person is happy"; "Songs make life merry and give a lot of joy. They give birth to a lot of phantasies and nice dreams..."; "Singing can be a career. I would like to have a career in music. When I sing, I get carried away into the song, I am merry, the world would not exist without music."; "Music helps me learn and think"; "A song can comfort my heart and stroke my body". 
The form of music and its content that reaches young people through information means these days do not always facilitate the choice of appropriate values or identification of their meaning and do not always positively influence development of esthetical taste of school learners. Junior school age learners are susceptible to everything and sensitive to emotional experiences, therefore a targeted influence on their imagination and feelings is particularly relevant. It is quite natural that acoustic environment has impact on the school learner's lifestyle, evokes need for aroused experiences (frequently linked with earsplitting sounds) and influences musicality.

According to T.A. Regelski (2006), "listening" has to be one of the most important practical activities in educational curricular seeking to enable school learners to understand that music as if conveys the internal life, experience of a person that they are also invited to take part in. Thus, it is important to ensure that while discussing the impressions experienced listening to popular music, school learners are able to assign meaning of associations that are relevant, important or desired to them. On the other hand, emotional state of school learners, their experience is reflected, their efforts to deepen knowledge, to improve character, behaviour become visible and the teacher is given directions in modelling of the educational process.

The following thoughts were expressed by school learners about listening to music: "Music leads me to the world full of imagination, where everybody is merry and happy"; "You can travel to the forest, fields and heaven together with music. Music is a bird flying above the whole world. Without music all the children would be sad"; "Music provides me with various feelings"; "I access the world. Music sounds everywhere, sometimes my ear starts hurting, sometimes I like being there very much, but when the music ends, I have to leave this world of music"; "Music has made up a considerable part of my life since I understood what is what. The world would be grey without music. It is practically impossible to live without sounds. Music helps me relax"; "When I listen to rock music, I imagine myself singing in the rock concert"; "If music were a human being, it would be my best friend. This is your happiness"; "I relax and travel to very nice islands, towns, flower gardens and the most beautiful places of Lithuania"; "If a person has never listened to music before, a new world may open to him or her, when s/he starts doing it"; "Music takes us to phantasies, kingdoms and dreams.......perhaps those dreams one day may become true. Nobody knows".

Certainly, organising listening to music, school learners are given the possibility of hearing the composition several times to enable them to penetrate into music and to recognise it. To facilitate joy created by recognition, school learners have to listen to different interpretations, orchestration and arrangements of the same composition, to compare various records trying to identify instruments, to analyse acoustic environment (proportion of music and non-music sounds, sounds employed in contemporary music) and to find visual equivalents of various forms of compositions.

Communication with school learners during musical activities can be fostered if a teacher expresses own feelings and this, consequently, encourages school learners to do the same, if more attention is allocated to school children's opinions and they are given time to think over their answers to open questions and if a teacher applies corrective feedback. This evokes learners' wish to penetrate into the musical activitysituation deeper. Through asking questions and commenting, attempts are made to follow thoughts of another person and to encourage school learners to look to the future.

The educational project allowed to test the possibility of nurturing manifestations of school learners' humanism in primary forms through integration of popular music. They are seen as a need for friendship that provides joy, a sense of understanding and, on the contrary, inhuman relations project dissatisfaction, disappointment, bad feelings and negative relations in the classroom. To support this relevant issue, the intents of activity can be adapted, and characteristic compositions can be chosen.

The episode of teaching the song "You and Me" (music by V. Noreikis, lyrics by A. Cibarauskas) is presented with Friendship as a prevailing intent.

Introductory conversation. Everybody would like to have good friends and to share joys. It is so pleasant, when somebody else tries to listen to you and understands you, respects your opinion and behaves in an honest way, is ready to help you and to do something good. Every day we have to communicate with a lot of people. Sometimes mutual misunderstandings, disagreements and conflicts occur, sometimes we lack friendliness and respect for each other. I would like to believe that disrespect or insulting behaviour does not occur among you. The individual's beauty is reflected in his/her inner world and good 
behaviour. Let us listen to a song created by contemporary Lithuanian authors. Try to put yourself into the world of own thoughts and feelings and into that of your friend. What mutual feeling of two people will be conveyed through music sounds: friendship or disagreement. Think what you could say to your friend. Listening to music.

Having discussed the heard music and text of the song, characteristics of friendship are identified (opinions of school learners: "true friends will always make it up", "sincere friendship as joy", "friendship is not necessary as a word, friendship is necessary for you to know that a friend will comfort, understand and listen to you", "it is sad without friends"). The learners are offered to perform the song in own way (taking into account the voice timber, mimics, highlighting the most important moments in the song) and to imagine various situations of its performing. For example: 1) it is pleasant, when we provide joy to a friend (everybody); 2) everybody has to make attempts to understand experiences of others.

Thus, through methods of personal meaning and emotional imitation not only individuality of cognitive processes but also the position of the percipient and his/her axiological attitude are revealed. All this enables communication with music in a way that provides with opportunities of better knowledge and understanding of the self and others. According to A. Piliciauskas (1998), it is important to direct psychical activity of learners to their life experience using introductory questions. This serves as a pretext to communicate with the ideal "me" the way communication occurs with others.

\section{Conclusions}

As is common knowledge, the conceptions of music education in different countries emphasise the importance of music education not only in learning music but also in development of a full-fledged personality. The success of music education also depends on the efforts of school learners themselves to perceive themselves as an individual as well as on positive emotions that accompany the process of music education, the evoking of which is related to favourite musical activities, experiences gained during them and created safe educational environment.

Thus, the educational project confirms that creating a coherent, consistent and targeted process of music education, which also integrates popular music, active (personal meaning and emotional imitation) methods of music education can be acceptable and efficient for junior school age children because they create preconditions for development of musicality and presupposition of transferable skills. Participating in activities, a school learner builds up relevant attitudes that condition motives for his/her behaviour. Popular music is liked by and well-known to school learners, therefore it is possible to expand the knowledge of music world in new ways applying the synthesis of the discussed methods and popular music.

All this as if creates a musical pretext to communicate with oneself and others establishing opportunities to look back and forward. This reveals not only individuality of cognitive activities but also a value-based attitude of the percipient. Therefore, this project presents one of the ways how to apply popular music in the process of education: introduction of the teacher that prepares school learners for perception of musical composition/activities $\rightarrow$ recognition of musical intonations, living through the composition $\rightarrow$ identification of musical experiences pointing out the perceived personal meaning $\rightarrow$ modeling of virtual situation of moral content $\rightarrow$ decision making $\rightarrow$ evaluation $\rightarrow$ respective perception. It is believed to strengthen links between the musical and value-based world of the school learner.

\section{Bibliography}

1. Bowman W. (2012). Music's Place in Education. In G.E. McPherson, G.F. Welch (Eds.), The Oxford Handbook of Music Education, 1, 21-39.

2. Carvalho S.H.M., Scavarda A. (2014). Music Economy Field Configuration: An Exploratory Study. In D. Forrest (Ed.), Proceedings of the International Society for Music Education. World Conference on Music Education, 31, 210-215.

3. Charvat J. (2003). Project Management Methodologies. New Jersey: John Wiley and Sons. Retrieved from http://www.maxwideman.com/papers/pm-methodologies/pm_methodologies.pdf

4. Davis S.G., Blair D.V. (2011). Popular Music in American Teacher Education: A Glimpse into a Secondary Methods Course. International Journal of Music Education, 29(2), 124-140.

5. Green L. (2006). Popular Music Education in and for Itself, and for "Other" Music: Current Research in the Classroom. International Journal of Music Education, 24(2), 101-118. 
6. Hedden D.G. (2010). Threading the Concept: Powerful Learning for the Music Classroom. USA: MENC.

7. Juvonen A. (2002). Music Education in Crises, Why and What to Do. Pedagogika (Pedagogy), 63, 7-14. International Scientific Conference to Commemorate the $45^{\text {th }}$ Anniversary since Establishment of the Subject of Music. Vilnius: Pedagogical University.

8. Juvonen A., Ruismaki H., Lehtonen K. (2012). Music Education Facing New Challenges. Procedia-Social and Behavioral Sciences, 45, 197-205.

9. Law W.W., Ho W.Ch. (2015). Popular Music and School Music Education: Chinese Students' Preferences and Dilemmas in Shanghai. International Journal of Music Education, 33(3), 304-324.

10. Mantie R.A. (2013). A Comparison of "Popular Music Pedagogy" Discourses. Journal of Research in Music Education, 61(3), 334-352.

11. Mark M., Madera P. (2014). Contemporary Music Education. Germany: Schirmer, Cengage Learning.

12. Navickiene L. (2005). Emocinio Imitavimo Metodas Muzikos Pamokoje (The Method of Emotional Imitation in a Music Lesson). Vilnius: Kronta.

13. Nilsson B., Folkestad G. (2005). Children's Practice of Computer-Based Composition. Music Education Research, 7(1), 21-37.

14. Piliciauskas A. (1998). Muzikos Pažinimas (Learning of Music). Book 2. Stadijos, rezultatai ir reikšmè (Stages, Results and Meanings). Vilnius: LAMUC.

15. Pradinio ir pagrindinio ugdymo bendrosios programos (General Curricular of Primary and Basic Education of Lithuania). (2008). Nr. ISAK-2433. Vilnius: Lietuvos Respublikos Švietimo ir mokslo ministrija.

16. Rauduvaite A. (2016). Possibilities of Popular Music Application Enhancing Music Education in the Context of School Learners' Socialisation. In Gerd-Bodo von Carlsburg (Eds.), Strategies for Teacher Training: Concepts for Improving Skills and Quality of Teaching. Frankfurt am Main: Peter Lang.

17. Regelski T.A. (2006). Music Appreciation as Praxis. Music Education Research, 8(2), 281-310.

18. Rodriguez C.X. (2012). Popular Music Ensembles. In G.E. McPherson, G.F. Welch (Eds.), The Oxford Handbook of Music Education. Oxford, UK: Oxford University Press, 878-889.

19. Sepp A., Ruokonen I. (2013). What are the main objectives of music teaching in music teachers' opinion? A Comparative Study Between Estonia and Finland. Problems in Music Pedagogy, 12(2), 7-16.

20. Springer D.G., Gooding L.F. (2013). Preservice Music Teachers' Attitudes Towards Popular Music in the Music Classroom. Journal of Music Teacher Education, 32(1), 25-33.

21. Wright R., Finney J. (2010). Culture, Society and Music Education. In R. Wright (Ed.), Sociology and music education. Farnham, UK: Ashgate, 223-241. 